\title{
Fotopedologia e pedologia espectral orbital associadas no estudo de solos desenvolvidos de basalto
}

\author{
José A. M. Demattê $\left({ }^{1 *}\right)$; Fernando Perobelli Ferreira $\left({ }^{2}\right)$; Marcelo Rodrigo Alves $\left({ }^{2}\right)$; \\ Rogério Costa Campos $\left({ }^{3}\right)$
}

(') Departamento de Ciência do Solo, Escola Superior de Agricultura Luiz de Queiroz (ESALQ-USP). Caixa Postal 9, 13418900

Piracicaba (SP), Brasil. E-mail: jamdemat@esalq.usp.br (*) Autor correspondente; celorrodrigo@yahoo.com.br

(2) Departamento de Engenharia Rural, Universidade Federal de Santa Catarina (UFSC). Rodovia Ademar Gonzaga, 1346 ,

88040-000 Florianópolis (SC). E-mail: ferreirafp@cca.ufsc.br

(3) Departamento de Engenharia Rural da Universidade Federal de Pelotas (UFPel), Caixa Postal 354, 96010900 Pelotas (RS) Brasil.

E-mail: rogerio.c.campos@hotmail.com

Recebido: 4/abr./2008; Aceito: 22/jun./2010

\begin{abstract}
Resumo
O Estado do Mato Grosso do Sul (MS) é um dos principais produtores do setor agropecuário brasileiro. Entretanto, para manter essa condição, terá que ter à disposição metodologias que auxiliem no planejamento do uso racional de suas terras. Desta forma, tornam-se necessárias pesquisas que visem obter métodos de investigação dos solos que atuem de forma rápida, sejam eficazes e, principalmente, de baixo custo. Sabendo-se que o relevo é importante fator de formação dos solos e que fotos aéreas detectam a variação de superfície, espera-se que, juntamente com informações espectrais quantitativas da superfície, possam caracterizar e discriminar solos ou grupamento de solos na paisagem. Assim, este estudo teve por objetivos: (a) identificar diferentes classes de solos e verificar suas relações com os aspectos qualitativos e quantitativos da paisagem; (b) utilizar dados radiométricos de imagens de satélite para discriminar classes ou grupamento de solos. Para tal, foi avaliada a relação entre a classificação dos solos e os aspectos da rede de drenagem, obtidos através da interpretação de fotografias aéreas, e dados espectrais, conseguidos através da análise de imagens de satélite, de 14 amostras circulares (ACs) da região de Maracaju (MS), onde os solos são desenvolvidos a partir de basaltos. A densidade de drenagem (Dd) apresentou correlação com o índice de intemperismo (Ki) e com a saturação de bases do solo (V\%), permitindo discriminar classes de solos dentro da área de estudo com 85,7 \% de certeza, enquanto os dados espectrais somente discriminaram solos quanto às classes texturais da camada superficial. Além disso, observou-se que nos solos com teores de $\mathrm{Fe}_{2} \mathrm{O}_{3}$ acima de $180 \mathrm{~g} \mathrm{~kg}^{-1}$ a diferenciação por classes texturais foi prejudicada mediante o do uso das imagens de satélite.
\end{abstract}

Palavras-chave: formas da paisagem; morfometria; imagens de satélite; reflectância.

\section{Photopedology and orbital spectral pedology on the evaluation of soils developed from basalt}

Abstract

The state of Mato Grosso do Sul (MS) is one of the main Brazilian producers in the agricultural sector. To maintain this status, however, it will be necessary both to know and use rationally its soil resources. This way, it will be necessary methods of soil research that are efficient and fast in obtain information, as well as of low-cost to support land use planning. Since relief is an important factor of soil formation, aerial photos and satellite images analysis can be used to detect landscape features that help to characterize and discriminate soils. Therefore, the goals of this study were: (a) to identify different soil classes and verify their relationships with landscape aspects by the interpretation of aerial photos; and (b) to use radiometric data, obtained from satellite images analysis, to discriminate soils or groups of soils on landscape. To do so, it was evaluated the relationship between soil classes and relief and drainage aspects, obtained by the interpretation of aerial photos in conjunction with spectral data obtained by satellite image analysis of 14 circular samples (CS) of the Maracaju city in the MS state. The drainage density (Dd), determined in the CS, showed positive correlation with the soil Ki index and base saturation (V\%) index, thus allowing discriminate soil classes of the studied area with $85.7 \%$ of certainty, whereas the spectral data only discriminated soils by the textural classes of their surface layer. On the other hand, it was also observed that soils with $\mathrm{Fe}_{2} \mathrm{O}_{3}$ content higher than $180 \mathrm{~g} \mathrm{~kg}^{-1}$ had their textural classes poorly differentiated by using the spectral data.

Key words: landform, morphometry, satellite images, reflectance. 


\section{INTRODUÇÃO}

O Estado do Mato Grosso do Sul (MS) está em franca expansão e grande desenvolvimento no setor agropecuário, fato comprovado pelos dados do Ministério da Agricultura, Pecuária e Abastecimento brasileiro de 2004, os quais mostram que, da safra 90/91 até a safra 03/04, as produçốes de soja, algodão e o rebanho bovino no Estado aumentaram em $45 \%, 24 \%$ e $20 \%$, respectivamente. Desta forma, maiores investigaçôes sobre seus os solos devem ser realizadas para que sirvam de auxílio no planejamento racional do uso de suas terras.

Os métodos de fotointerpretação de solos, por estudarem aspectos da superfície terrestre como os padróes do relevo e da rede de drenagem, são considerados de alta correlação com as diferentes classes de solos existentes (BURINGH, 1960; Goosen, 1968), pois refletem seus atributos internos e limites (Lueder, 1959; Goosen, 1968). São também de fácil observação e determinação, o que facilita bastante seu estudo, independentemente da área abrangida (CARVALHO et al., 1990). Ademais, por apresentar como principais vantagens a redução do tempo dos trabalhos de campo e os custos dos levantamentos pedológicos (BURINGH, 1960; Goosen, 1968), no Brasil, o estudo dos solos por fotografias aéreas há décadas tem sido realizado.

Contudo, estudos envolvendo a caracterização de solos e sua correlação com padrôes do relevo e da drenagem ainda são insuficientes (CARVAlHo et al., 1990; França e Demattê, 1991; França e Demattê, 1993; Demattê e Demétrio, 1998; Reddy et al., 2004; PissarRA et al., 2004). Esse fato faz com que informaçóes fotomorfopedológicas de importantes regióes produtoras do país, como por exemplo o Estado do Mato Grosso do Sul, sejam escassas e, consequentemente, os processos envolvidos na diferenciação de solos na paisagem por este sistema, não estấo completamente entendidos.

O relevo é um dos principais agentes de formação do solo, atuando na sua formação tanto de forma indireta quanto direta, pois pode modificar características climáticas de uma determinada região e controlar sua drenagem respectivamente (Moniz, 1972). Além disso, suas formas geralmente refletem características geológicas e a atuação dos processos de formação pedogenética.

A rede de drenagem é a característica mais importante do relevo a indicar diferenças entre solos e rochas, pois suas características advêm da interaçấo de fatores associados ao relevo, geologia, clima, vegetação, textura e permeabilidade do solo. Nesse caso, o padrão da rede de drenagem, definido pelo arranjo espacial dos rios e seus afluentes, também tem sido amplamente explorado na definição de zonas homólogas em estudos de segmentaçáo do meio físico.

No entanto, com a grande explosão tecnológica das últimas décadas, outros tipos de ferramentas de análises também têm surgido e o estudo dos solos e da paisagem através de imagem por satélites vem sendo de grande valia.
Por exemplo, Reddy et al. (2004), demonstraram que a interpretação de dados gerados por satélites multiespectrais também ajudam na análise de parâmetros da drenagem e na delimitaçáo de distintas unidades geológicas e da paisagem. Há, entretanto, uma lacuna na produção científica que integre a informação do relevo com as das imagens de satélite e que também necessita ser mais bem estudada.

Assim, os objetivos deste estudo foram: a) identificar diferentes classes de solos e verificar suas relaçóes com os aspectos qualitativos e quantitativos da paisagem (relevo e drenagem) através do uso de fotografias aéreas e b) utilizar dados radiométricos de imagens geradas pelo satélite Landsat $7 \mathrm{ETM}^{+}$para discriminar classes de solos.

\section{MATERIAL E MÉTODOS}

\section{Área de estudo e levantamento pedológico}

A área de estudo localiza-se no município de Maracaju (MS), entre as coordenadas geográficas $43^{\circ} 32^{\prime} 06^{\prime \prime}$ e $43^{\circ} 22^{\prime} 44^{\prime \prime}$ (Longitude oeste) e $21^{\circ} 26^{\prime} 38^{\prime \prime}$ e $21^{\circ} 15^{\prime} 43^{\prime \prime}$ (Latitude Sul). $\mathrm{Na}$ regiāo, há predomínio de rochas básicas da formação Serra Geral, observadas sobre arenitos da Formação Botucatu que são capeados por arenitos continentais fluviais e lacustres das formaçóes Bauru e Aquidauana (BrASIL, 1982).

\section{Levantamento pedológico e atributos foto- pedológicos}

Primeiramente, foi realizado o levantamento pedológico em nível semidetalhado da área estudada, conforme metodologia proposta por EMBrApa (1995), tomando-se como base a carta planialtimétrica da área de estudo na escala de 1:25.000 e fotografias aéreas verticais com escala aproximada de 1:60.000. A descrição dos perfis selecionados e a coleta de amostras para fins de classificação foram realizadas de acordo com SANTOS et al. (2005); a caracterização físicoquímica dos solos foi realizada a partir de amostras secas ao ar (TFSA) segundo EMBrapa (1997); e a classificação dos solos, realizada de acordo com EMBRApa (2006).

Posteriormente, baseando-se no mapa semidetalhado de solos e no mapa da rede de drenagem, a qual foi traçada com a utilização de estereoscópios de espelhos como parte do trabalho de fotointerpretação, foram locadas na área de estudo 14 amostras circulares (ACs) contendo 20 $\mathrm{km}^{2}$ cada um (Figura 1). Depois de locadas as ACs, com a ajuda de um curvímetro e um planímetro, o comprimento total da rede de drenagem $(\mathrm{km})$ e a porcentagem de ocorrência dos solos dentro de cada AC foram determinados respectivamente. Solos com ocorrência restrita nas ACs, por não interferirem nas conclusões deste estudo, foram desconsiderados. Entretanto, esse fato foi observado apenas nas ACs 7 e 10. 
$\mathrm{O}$ índice relacionado à rede de drenagem analisado foi a densidade de drenagem (Dd), obtido pela divisão do comprimento total da rede de drenagem $(\mathrm{km})$ pela área total de cada $\mathrm{AC}\left(\mathrm{km}^{2}\right)$. Posteriormente, as ACs foram avaliadas com base nas características descritivas do relevo, da drenagem e da classificação dos solos (Tabela 1) (SANTOS et al., 2005).

\section{Coleta e avaliação dos dados espectrais}

Para a caracterização espectral, uma imagem da área de estudo gerada pelo satélite Landsat $7 \mathrm{ETM}^{+}$foi utilizada. As bandas espectrais utilizadas neste estudo foram: ETM1 (9450 - $520 \mathrm{~nm})$, ETM2 (520-600 nm), ETM3 (630-690 nm), ETM4 (760-900 nm), ETM5 (1150$1750 \mathrm{~nm})$ e ETM7 (2080-2350 nm). No tratamento da imagem e na obtenção das reflectâncias e curvas espectrais nas ACs selecionadas, o software Spring (INPE, 2003) foi utilizado para o georreferenciamento dos pontos amostrais na imagem de satélite e o software ENVI (Environment for Visualizing Images) para o tratamento das imagens e à extraçáo das curvas espectrais dos pontos selecionados.

A imagem de satélite foi primeiramente calibrada e processada para o nível de reflectância no topo da atmosfera. Este procedimento, que permite que se obtenha a imagem reflectância da superfície pela remoção do efeito da atmosfera, foi obtido através da aplicação do modelo $5 \mathrm{~S}$ (Solar Spectra Satellite Signal Simulation) à imagem utilizada, e desenvolvido pelo Atmospheric Optical Laboratory, France (TANRÉ et al,. 1992). Depois dessa correção, três critérios foram empregados para identificar pixels de solo exposto na imagem reflectância: (a) a análise da linha do solo, onde se identifica pixels próximos a linha 1:1 formada pela dispersão dos valores de reflectância coletados das bandas ETM3 e ETM4 (Figura 2), indicativa de solo exposto (BARET et al.,

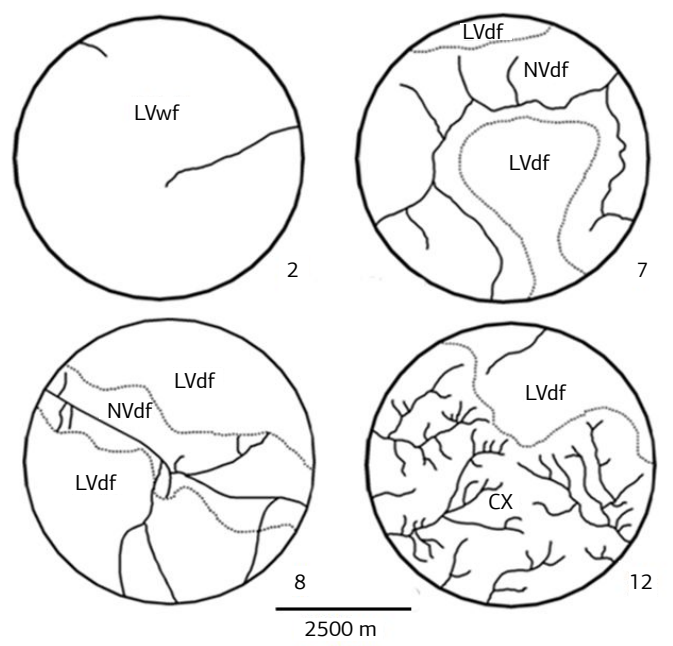

Figura 1. Principais amostras circulares contendo a variação de classes de solos e da rede drenagem na área de estudo.

Tabela 1. Descrição das características qualitativas do relevo e da drenagem na área de estudo

\begin{tabular}{|c|c|}
\hline Características & Descrição \\
\hline \multicolumn{2}{|l|}{ Relevo } \\
\hline Tipo & $\begin{array}{l}\text { Normal, subnormal e excessivo, representando respectivamente áreas com infiltração > } \\
\text { deflúvio; deflúvio > infiltração; infiltração = deflúvio. }\end{array}$ \\
\hline Classe & $\begin{array}{l}\text { Quanto às classes o relevo pode ser: plano }(0-3 \%) \text {, suave ondulado }(3-8 \%) \text {, ondulado } \\
(8-20 \%) \text {, forte ondulado }(20-45 \%) \text { e montanhoso e escarpado }(>45 \%) \text {; }\end{array}$ \\
\hline Forma da vertente & Côncava, convexa ou plana; \\
\hline Comprimento da vertente & Longa, média ou curta; \\
\hline Uniformidade & Pouco uniforme, uniforme ou desuniforme; \\
\hline Gradiente & Forte, moderado ou baixo. \\
\hline \multicolumn{2}{|l|}{ Drenagem } \\
\hline Tipo ou modelo & $\begin{array}{l}\text { Quanto ao aspecto do conjunto de canais existem diversos tipos, entre eles estão: } \\
\text { subdendrítico, dendrítico, anelar, angular, subparalelo, paralelo, radial, anastomático; }\end{array}$ \\
\hline Grau de Integração & $\begin{array}{l}\text { Refere-se ao caminhamento dos canais entre dois pontos. Quanto mais curto esse } \\
\text { caminhamento, maior a integração. Assim, têm-se as classes: baixo ou alto; }\end{array}$ \\
\hline Densidade & $\begin{array}{l}\text { Refere-se ao número de canais por unidade de área. Quanto maior o número de canais por } \\
\text { unidade de área, maior a densidade. Um padrão com alta densidade é constituído por alto } \\
\text { número de canais próximos entre si. Assim, têm-se as classes: alta, média e baixa; }\end{array}$ \\
\hline Grau de Uniformidade & $\begin{array}{l}\text { Uma rede de drenagem é uniforme, quando o padrão não se altera se examinado como } \\
\text { um todo. Um padrão não uniforme possui áreas com subpadrões individuais distintos das } \\
\text { demais; }\end{array}$ \\
\hline Grau de Controle & $\begin{array}{l}\text { Refere-se à presença de fatores que alteram o sentido normal da rede de drenagem. } \\
\text { Ele indica se está ou não havendo um controle da rede de drenagem, pela rocha. Este } \\
\text { parâmetro está intimamente ligado ao aspecto angularidade e orientação; }\end{array}$ \\
\hline Orientação & $\begin{array}{l}\text { Refere-se à presença de aspectos direcionais no caminhamento descendente normal dos } \\
\text { cursos de água. Podendo ser classificada como orientada ou não orientada; }\end{array}$ \\
\hline Angularidade & $\begin{array}{l}\text { Refere-se à presença de mudanças abruptas, no caminhamento dos canais. Pela observação } \\
\text { da angularidade, se tira inferências sobre o grau de controle. Ela pode ser alta, média, baixa } \\
\text { ou ausente; }\end{array}$ \\
\hline Ângulos de Confluência & É o ângulo formado na foz de um tributário com o seu receptor. \\
\hline
\end{tabular}


1993); (b) porcentagem de cobertura do solo obtida com base nos valores do índice de vegetação "Soil Adjust Vegetation Index" (Savi; Huete, 1989); (c) análise visual da imagem nas composiçōes RGB (ETM5/ETM4/ETM3 e ETM3/ETM2/ ETM1) dos pixels classificados como de solo exposto. Depois de aplicados os critérios apresentados acima, foram coletados os espectros dos solos incluídos na análise.

\section{Análise dos resultados}

Foram realizadas análises de correlaçáo entre os atributos químicos dos solos e os valores de Dd obtidos nas ACs. Neste caso, considerou-se a média ponderada dos atributos químicos dos solos em relação à porcentagem de ocorrência de cada classe de solo dentro das ACs.

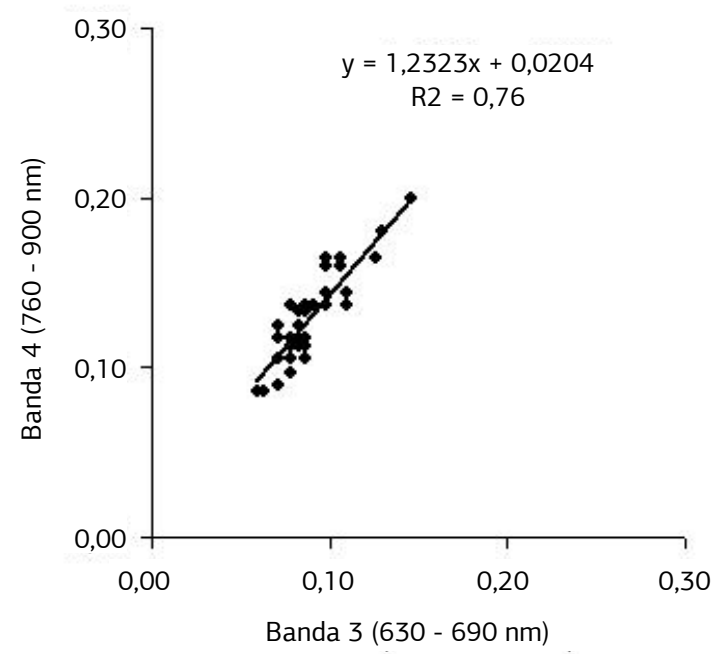

Figura 2. Linha do solo obtida pela relação dos valores de reflectância das bandas ETM3 e ETM4 do satélite Landsat 7 ETM ${ }^{+}$ da área de estudo.
Através da distribuição das classes de solos nas ACs, três grupos de ACs foram formadas e as médias da Dd e dos dados químicos de cada grupo comparadas pelo teste t de Student a $5 \%$. Este procedimento foi realizado com o propósito de avaliar os aspectos quantitativos da drenagem e a variabilidade dos dados químicos e mineralógicos dos solos de cada grupo de ACs.

Além disso, com o objetivo de agrupar ACs similares, também foi aplicada aos valores de Dd obtidos, uma análise multivariada de agrupamento, sendo utilizado como método de delimitação dos grupos, a ligação entre grupos ("Between-groups linkage"), e como medida de similaridade, a distância euclidiana. Os resultados foram apresentados na forma de dendrograma, permitindo a visualização das distâncias entre as 14 variáveis. Neste diagrama, a escala varia de zero (amostras similares) a 25 (amostras sem similaridades). Todas as análises estatísticas foram realizadas com o auxilio do programa SPSS versão 11.0.

\section{RESULTADOS E DISCUSSÃO}

\section{Análise qualitativa das amostras circulares}

As classes de solos identificadas na área de estudo foram: Latossolo Vermelho Acriférrico típico (LVwf); Latossolo Vermelho Distroférrico típico (LVdf), Nitossolo Vermelho Distroférrico típico (NVdf); Nitossolo Vermelho Distroférrico latossólico (NVdf-1); e o Cambissolo Háplico Distroférrico típico (CXdf) (Embrapa, 2006).

As características do relevo indicam diferentes compartimentos da paisagem, onde ocorrem diversos processos superficiais e subsuperficiais. Quando estas características são analisadas na área de estudo (Tabela 2), verifica-se que o LVwf, o LVdf, o NVdf e o NVdf-1 são muito similares

Tabela 2. Resultados dos aspectos descritivos do relevo e da drenagem dos solos da área de estudo

\begin{tabular}{|c|c|c|c|c|}
\hline \multirow{2}{*}{ Características } & \multicolumn{4}{|c|}{ Solos } \\
\hline & LVwf/LVdf & NVdf-1 & NVdf & CXdf \\
\hline \multicolumn{5}{|c|}{ Relevo } \\
\hline Tipo & Normal & Normal & Normal & Excessivo \\
\hline Classe & Plano & SVO (1) & Plano /SVO & $\mathrm{FtO}\left({ }^{2}\right)$ \\
\hline Forma da vertente & Convexa & Convexa & Convexa & Côncava/Rt. \\
\hline Comp. da vertente & Muito Longa & Longa & Muito Longa & Curta \\
\hline Uniformidade & Uniforme & Uniforme & Uniforme & Pouco Uniforme \\
\hline Gradiente & Suave & Moderada & Moderado & Forte \\
\hline \multicolumn{5}{|c|}{ Drenagem } \\
\hline Tipo ou modelo & Subparalelo & Subparalelo & Subparalelo & Paralelo \\
\hline Grau de integração & Baixa & Alto & Alto & Alto \\
\hline Densidade & Baixa & Baixa & Baixa & Média \\
\hline Grau de uniformidade & Uniforme & Uniforme & Uniforme & Uniforme \\
\hline Grau de controle & Baixo & Médio & Baixo & Médio \\
\hline Orientação & Orientado & Orientado & Orientado & Orientado \\
\hline Angularidade & Ausente & Ausente & Ausente & Média \\
\hline Ângulos de confluência & Agudo & Agudo & Agudo & Agudo \\
\hline
\end{tabular}

(1) $\mathrm{SVO}=$ suave ondulado;

(2) $\mathrm{FtO}=$ Forte ondulado 
quanto aos seus aspectos descritivos, apresentando tipo normal, classe variando de plano a suave ondulado, forma da vertente convexa, comprimento da vertente variando de longa a muito longa, relevo uniforme e gradiente variando de suave a moderado.

O CXdf é um solo bem distinto dos primeiros em relação ao relevo, diferindo destes em todas as características (Tabela 2). Os Cambissolos, por definição, são solos horizonte $\mathrm{B}$ inicipiente $(\mathrm{Bi})$, isto é, horizonte mineral com desenvolvimento suficiente para o aumento de cor e estrutura (EMBRAPA, 2006). Assim, são solos em transformação e que ainda não têm características morfológicas suficientes expressas para serem enquadradas em outras ordens de solo.

Além disso, os CXdf podem ser encontrados em várias situaçôes de relevo (STRECK et al., 2002), sendo neste estudo, entretanto, a maioria observado em relevo forte ondulado. Essa condição de relevo condiciona ao CXdf uma menor relação Infiltração/Deflúvio (I/D) em relação aos demais solos da área (LVwf, LVdf, NVdf-1 e NVdf), os quais tendem a ocorrer em relevos mais planos, retardando em partes seu desenvolvimento pedogenético.

Este resultado está de acordo com os obtidos por FranÇA e Demattê (1990), os quais explicam que em solos profundos e bem drenados, por ocorrer em relevos mais planos e estáveis, há menor número de rios e ou canais por unidade de área, e por consequência, maior infiltraçáo de água e menor escorrimento superficial; em solos localizados em relevos mais acidentados há maior número de rios e/ou canais por unidade de área e, consequentemente, menor relação I/D.

Em relação às características do padrão de drenagem, estas repercutem o comportamento hidrológico e litológico de cada solo. Assim, observa-se nos Latossolos (LVwf e LVdf) um grau de integração dos rios baixa, isto é, maior distância de interligação entre os canais, bem como baixa densidade da rede de drenagem. Esse processo está relacionado ao fato de esse tipo de solo estar localizado em situação de topo na paisagem, o que favorece o intemperismo, principalmente as reaçóes de hidrólise e oxidação, e faz com que seja, no geral, profundo e com drenagem interna muito boa, devido ao tipo de estrutura formada.

Os Nitossolos (NVdf-1 e NVdf) têm características similares entre si e em partes similares aos Latossolos da área de estudo, exceto pelo maior grau de integração de seus rios, o que se deve, neste caso, ao fato de serem encontrados em relevo suave ondulado (NVdf-1) ou intermediário entre plano/suave ondulado (NVdf) dentro da área de estudo. Esse fato proporciona uma relação I/D um pouco menor em relaçáo aos Latossolos, mas ainda o suficiente para o intemperismo atuar de forma intensa.

O CXdf, possui característica de drenagem bem diferenciada dos solos anteriores, compreendendo um tipo ou modelo de drenagem paralelo, com alto grau de integração entre os canais e uma Densidade da drenagem média, justamente pelo fato de ocorrer em relevos ondulados e geralmente associados aos Neossolos Litólicos. Desta forma, verifica-se que as características qualitativas do relevo e da rede de drenagem são intrínsecas de cada classe de solo e podem ser utilizadas como parâmetros auxiliares na diferenciação dos solos da área de estudo.

\section{Análise quantitativa da rede de drenagem}

O padrão de drenagem típico dos solos da área de estudo é mostrado na figura 1 e a porcentagem de ocorrência de solos bem como os valores de $\mathrm{Dd}\left(\mathrm{km} \mathrm{km}^{-2}\right)$ em cada AC na tabela 3. No geral, observou-se que das ACs $1-13$, a Dd aumentou e, portanto, o relevo ficou mais ondulado e dissecado na paisagem, condicionando a presença/ ausência dos solos estudados. Especificamente, das ACs 1-5 e 13-14, ocorreu a predominância de Latossolos; das ACs 6-10 ocorreu a associação Latossolos+Nitossolos; na

Tabela 3. Porcentagem dos solos e valores quantitativos da rede de drenagem nas 14 amostras circulares estudadas da região de Maracaju (MS)

\begin{tabular}{|c|c|c|c|c|c|c|c|}
\hline \multirow{2}{*}{$\begin{array}{l}\text { Amostra (') } \\
\text { circular }\end{array}$} & \multicolumn{5}{|c|}{ Solos (\%) } & \multirow{2}{*}{ Dd } & \multirow{2}{*}{ Drenagem } \\
\hline & LVwf & LVdf & NVdf & NVdf-1 & $C X$ & & \\
\hline 1 & 100 & & - & - & - & 0,20 & 3 \\
\hline 2 & 100 & & - & - & - & 0,15 & 3 \\
\hline 3 & 100 & & - & - & - & 0,36 & 3 \\
\hline 4 & 100 & & - & - & - & 0,60 & 3 \\
\hline 5 & 100 & & - & - & - & 0,39 & 3 \\
\hline 6 & - & 78,0 & 22,0 & - & - & 0,42 & $3-4$ \\
\hline $7^{2}$ & - & 25,6 & 68,7 & - & - & 0,60 & $3-4$ \\
\hline 8 & - & 69,0 & 31,0 & - & - & 0,75 & $3-4$ \\
\hline 9 & - & 61,5 & 38,5 & - & - & 0,75 & 3 \\
\hline $10{ }^{(2)}$ & - & 30,4 & - & 56,7 & - & 0,90 & $3-4$ \\
\hline 11 & - & - & - & 22,3 & 77,7 & 1,31 & $5-4$ \\
\hline 12 & - & 17,0 & - & - & 83,0 & 1,20 & $5-4$ \\
\hline 13 & 100 & & - & - & - & 0,38 & 3 \\
\hline 14 & 100 & & - & - & - & 0,11 & 3 \\
\hline
\end{tabular}

(1) Amostra circular com $20 \mathrm{~km}^{2} ;\left(^{2}\right)$ Amostras circulares que apresentaram classes de solos de ocorrência restrita e que năo foram considerados na análise; portanto, o total da área abrangida foi $<100 \%$. 
AC 11 a associação Nitossolo+Cambissolo; e na AC 12, a associação Latossolo+Cambissolo. Neste caso, à medida que os canais de drenagem ficaram com menor extensão, passaram a ocorrer com maior frequência, aumentando a Dd e condicionando a variação dos solos na paisagem.

Assim, observou-se que nas ACs que continham somente Latossolos, a Dd variou de 0,11 a $0,60 \mathrm{~km} \mathrm{~km}^{-2}$ (Tabela 3), enquanto nas demais, a Dd variou de 0,42 a $1,31 \mathrm{~km} \mathrm{~km}^{-2}$. Nas últimas, a $\mathrm{AC}$ com maior $\mathrm{Dd}$ foi a $\mathrm{AC} 11$, em que $77,7 \%$ de sua área é recoberta por CXdf e 22,3\% com NVdf-1, enquanto a AC com a menor Dd foi a AC 6, com 78,0\% e 22,0\% de sua área recoberta por $\mathrm{LVdf}$ e $\mathrm{NVdf}$ respectivamente.

Os menores valores de Dd para as ACs contendo Latossolos ocorrem devido a estes serem desenvolvidos sob relevo plano e mais estável (PIssarra et al., 2004). Entretanto, à medida que o relevo tende a ficar mais ondulado, os valores médios da Dd aumentam, resultando em maior dificuldade para a água se infiltrar no solo devido à ondulação do terreno. Por esse motivo, o escoamento superficial é mais intenso e provoca maior dissecação hídrica do terreno, sendo portanto, considerado indicativo da necessidade de maiores cuidados no seu manejo, uma vez que, principalmente sob fluxos concentrados de água, há menor resistência ao escavamento vertical.

Comparando os dados quantitativos da rede de drenagem das ACs contendo Latossolos deste estudo com a de outros estudos similares já realizados no Brasil, como por exemplo, os Latossolos de Corbélia, Paraná ( $\mathrm{Dd}=1,14$; Demattê e Demétrio, 1996a) e os Latossolos de Jaboticabal, São Paulo ( $\mathrm{Dd}=0,8$; Pissarra et al., 2004), observa-se que os valores observados na área de Maracaju são menores.

Estas variaçóes geralmente refletem a posição no relevo e o grau de controle da rocha sobre a rede de drenagem, porém, especificamente para Latossolos, os estudos consultados convergem a valores similares e próximos a $1,0 \mathrm{~km}$ $\mathrm{km}^{-2}$. Assim, os menores valores de Dd observados nas ACs contendo Latossolos, provavelmente devem-se ao fato destes atossolos localizarem-se em um relevo plano o suficiente para condicionar maior grau de ação do intemperismo, o que pode ser denotado pelo caráter ácrico observado nos Latossolos de algumas amostras circulares e que conduziu sua classificação como Latossolo Vermelho Acriférrico típico (LVwf).

Além do caráter ácrico, outra maneira de avaliar o grau de intemperismo dos solos é através do uso de índices que sugerem o grau de evolução mineralógica, como por exemplo, o índice Ki

$$
\left(\mathrm{Ki}=\frac{\mathrm{SiO}_{2}}{\mathrm{Al}_{2} \mathrm{O}_{3}} \times 1,7\right)
$$

(Moniz, 1973), a capacidade de troca de cátions da fração argila (CTC), bem como a relação silte/argila. A análise do desenvolvimento e número de horizontes pedogenéticos e diagnósticos presentes no perfil do solo também servem de referencial (BIRKELAND, 1984).
Neste estudo, observou-se uma correlação positiva e altamente significativa entre a Dd e o índice Ki $(r=0,911$; Figura 3a), o que concorda com os estudos realizados por Demattê e Demétrio (1996a,b). Assim, a Dd neste estudo, também pode ser utilizada para indicar o grau de intemperismo dos solos da regiáo estudada, bem como servir de parâmetro na identificação de diferentes classes.

$\mathrm{Na} \mathrm{Dd}$, apesar de baixa $(\mathrm{r}=0,629)$, também se notou correlaçáo positiva com a saturaçáo de bases do solo (V\%) (Figura 3b), ou seja, à medida que a Dd aumenta, a V\% também aumenta. Este resultado, provavelmente, deve-se ao fato de os solos com maior Dd tendem a ser menos hidrolisados e, portanto, menos lixiviados, condicionando menor perda de sílica e de cátions básicos $\left(\mathrm{Ca}^{+2}, \mathrm{Mg}^{+2}\right.$, $\mathrm{Na}^{+1}$ e $\mathrm{K}^{+1}$ ) durante sua evolução pedogenética.

\section{Análise por grupos de solos classificados pelo método convencional}

A fim de se realizar uma análise do efeito da Dd e dos atributos químicos e mineralógicos na discriminação das classes de solos da área de estudo, as ACs foram divididas em três grupos distintos: grupo 1 , contendo as $\mathrm{ACs}$ somente com Latossolos (ACs: 1-5, 13 e 14); grupo 2, contendo as ACs Latossolos associados a Nitossolos (ACs: 6-10); grupo 3 , contendo ACs com Cambissolos associados ou a Nitossolos ou a Latossolos (ACs: 11 e 12 respectivamente).

Somente a Dd e o índice Ki foram eficientes na diferenciação dos solos, isto é, foram estatisticamente diferentes entre os grupos de ACs formados. Assim, no grupo dos Latossolos, as amostras tiveram valor médio de $\mathrm{Dd}$ de $0,31 \mathrm{~km} \mathrm{~km}^{-2}$ e Ki de 1,4, no grupo 2 (Latossolo+ Nitossolo) a Dd média foi de $0,68 \mathrm{~km} \mathrm{~km}^{-2}$ e o Ki médio de 1,62 e no grupo 3 (principalmente Cambissolos) a Dd média foi de 1,26 km km e $^{-2}$ o Ki médio de 2,25.

A diferenciação classes ou grupos de solos pela Dd já havia sido relatada por Manzoli Junior (1990), DemattÊ e Demétrio (1996a,b) e Pissarra et al., (2004). Estes autores salientaram que, no geral, ACs com menores valores de $\mathrm{Dd}$, como as do grupo 1 deste estudo, que tiveram maior relação $\mathrm{I} / \mathrm{D}$, também possuem menores valores de CTC, $\mathrm{V} \%, \mathrm{Ki}, \mathrm{SiO}_{2}$ e maiores teores de óxi(hidróxidos) de $\mathrm{Fe}$ e óxidos de $\mathrm{Al}$ em relaçáo às $\mathrm{ACs}$ com valores de $\mathrm{Dd}$ mais elevados (grupos 2 e 3 ).

\section{Análise de agrupamento hierárquico da Densidade de drenagem (Dd)}

Como somente os índices Dd e Ki apresentaram diferença significativa entre os grupos estudados e, levando-se em consideração que esses índices estão altamente correlacionados, o que não justificaria utilizar as duas variáveis, foi aplicado a análise de agrupamento sobre os valores de $\mathrm{Dd}$ 
das 14 ACs para avaliar a potencialidade desta metodologia em discriminar as classes de solos.

Desta forma, observando-se o dendrograma (Figura 4), também foi possível separar as ACs em três grupos a partir da Dd. O grupo 1 foi composto pelas ACs com valores de Dd variando de 0,11-0,6 $\mathrm{km} \mathrm{km}^{-2}$ (amostras 1, 2, 3, 5, 6, 13, 14); o grupo 2 pelas ACs com valores de Dd variando de 0,6-0,9 $\mathrm{km} \mathrm{km}^{-2}$ (ACs: 4, 7, 8, 9 e 10); e o grupo 3 pelas ACs com valores de Dd variando de 1,20 - 1,31 (ACs: 11 e 12). Estes grupos são muito similares aos grupos previamente definidos, e apenas as ACs 4 e 6 trocaram de grupo. A AC 4 que previamente havia sido agrupada no grupo 1, passou para o grupo 2 e a AC 6, que havia sido agrupado no grupo 2, passou para o grupo 1 .

Com estes resultados, verificou-se que os agrupamentos tiveram uma eficiência geral de $85,7 \%$ de acerto sobre a
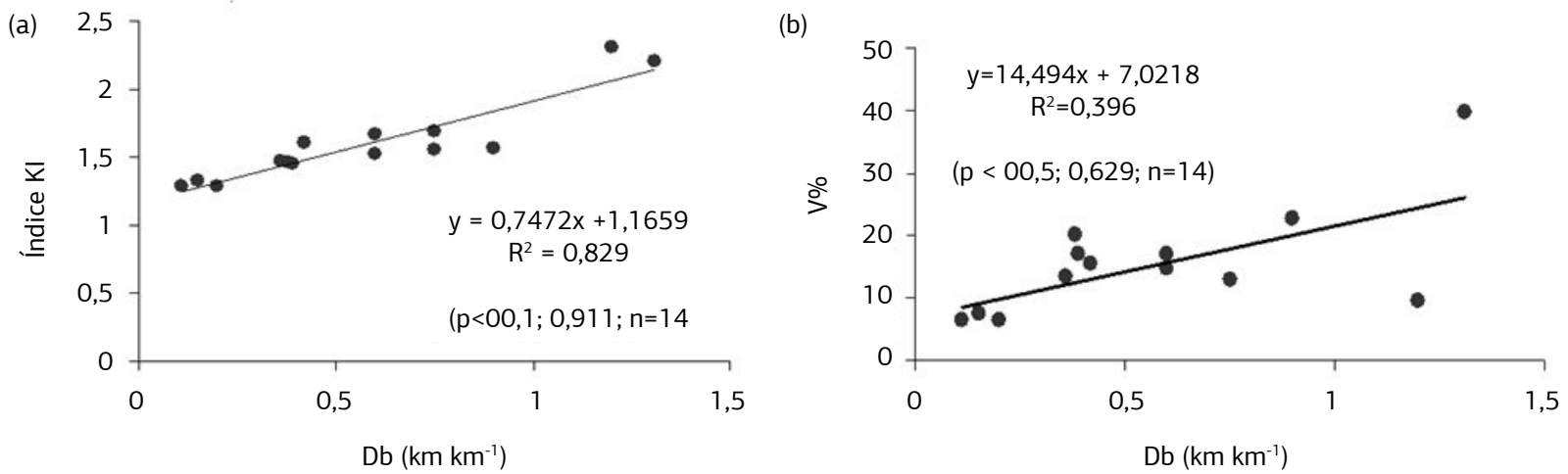

Figura 3. Correlação entre os dados de densidade de drenagem e o índice ki (a) e a saturação de bases (v\%) (b) dos solos da área de estudo.

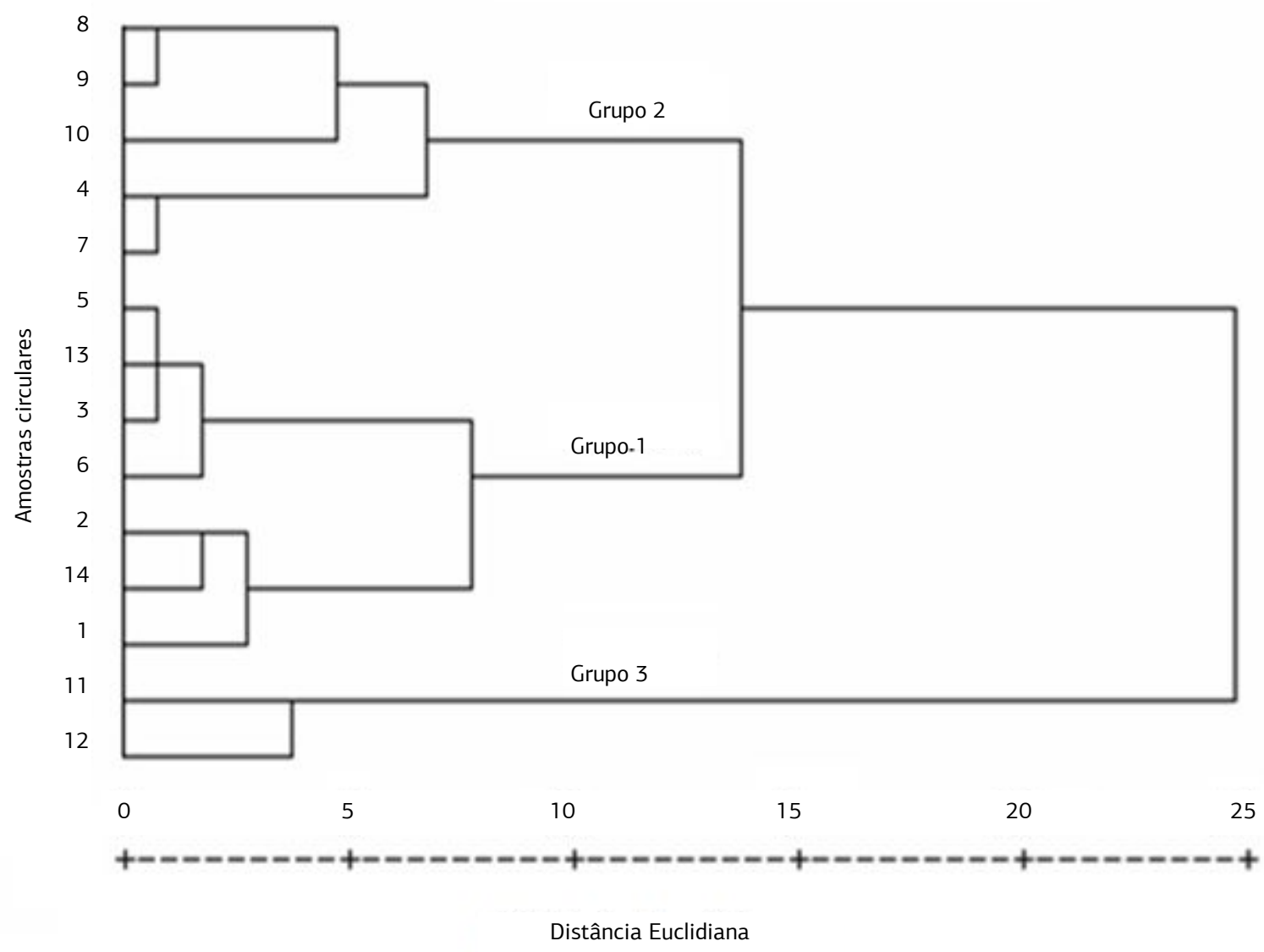

Figura 4. Dendrograma de análise de cluster dos valores de densidade de drenagem das 14 amostras circulares obtidas na regiāo de Maracajú (MS). 
classificação de Dd (Tabela 5). Além disso, estatisticamente, $85,7 \%$ das amostras do grupo $1,80 \%$ das amostras do grupo 2 e $100 \%$ das do grupo 3 foram classificadas corretamente e, mesmo com menor eficiência para o grupo 2, este apresentou apenas uma troca de agrupamento de AC dentro do grupo previamente estabelecido.

Entretanto, embora seja comprovado que grupos de solos podem ser inferidos através dos resultados de Dd, ressalta-se que só é possível associar estes grupos formados pelo programa estatístico a classes de solos, se houver um conhecimento prévio dos padrôes de Dd de cada classe de solo. Por exemplo, baseando-se nos dados anteriormente discutidos, sabe-se que para a região de estudo, as ACs com predominância de $\mathrm{LV}$ wf tem valores de $\mathrm{Dd}$ em torno de $0,31 \mathrm{~km} \mathrm{~km}^{-2}$, que as AC com predominância de NVdf e NVdf-1 tem valores de

Tabela 4. Valores médios, erro padrão, coeficiente de variação $(\mathrm{CV}$ $\%)$ e valores máximos e mínimos da densidade de drenagem (Dd) e índice Ki dos solos contidos nos grupos de amostras circulares da área de estudo

\begin{tabular}{|c|c|c|c|c|}
\hline \multirow{2}{*}{ Atributo } & \multirow{2}{*}{ Valor } & \multicolumn{3}{|c|}{ Grupo } \\
\hline & & 1 & 2 & 3 \\
\hline \multirow[t]{5}{*}{ Dd } & Média & $0,31 \mathrm{a}$ & $0,68 b$ & $1,26 \mathrm{c}$ \\
\hline & Erro-padrão & 0,06 & 0,08 & 0,06 \\
\hline & CV (\%) & 54,67 & 26,57 & 6,20 \\
\hline & Mínimo & 0,11 & 0,42 & 1,20 \\
\hline & Máximo & 0,60 & 0,90 & 1,31 \\
\hline \multirow[t]{5}{*}{$\mathrm{Ki}$} & Média & $1,40 a$ & $1,62 \mathrm{~b}$ & $2,25 c$ \\
\hline & Erro-padrão & 0,04 & 0,03 & 0,05 \\
\hline & CV (\%) & 6,80 & 3,90 & 3,14 \\
\hline & Mínimo & 1,29 & 1,55 & 2,20 \\
\hline & Máximo & 1,52 & 1,69 & 2,30 \\
\hline
\end{tabular}

Médias com mesma letra minúscula na linha não diferem estatisticamente entre si pelo teste de T de Studend ( $\mathrm{p}<0,05)$.
Dd em torno de $0,7 \mathrm{~km} \mathrm{~km}^{-2} \mathrm{e}$ que as amostras com CXdf têm valores de $\mathrm{Dd}$ em torno de $1,25 \mathrm{~km} \mathrm{~km}^{-2}$. Desta forma, é possível associar que os grupos 1, 2 e 3, estatisticamente formados, indicam ACs com a predominância de Latossolos, Nitossolos e Cambissolos respectivamente.

Além disso, fatores como o tipo de material de origem e o clima, também podem vir a exercer grande influência nos padrôes de drenagem e avaliar a viabilidade de utilizaçáo dos índices de drenagem como prováveis indicadores de intemperismo e identificadores de classes de solos derivados de vários materiais de origem e climas também seria interessante. Ainda, se esse tipo de estudo for realizado em ACs mais homogêneas, a separação dos solos pelos dados de Dd provavelmente será mais nítido.

\section{Análise dos solos por dados espectrais do satélite Landsat-7TM+}

$\mathrm{Na}$ linha do solo apresentada neste estudo (Figura 2), é perceptível a influência dos teores de argila e óxidos de

Tabela 5. Análise de acerto e erro entre os grupos formados pela análise de agrupamento dos valores de densidade de drenagem (Dd) das amostras circulares da área de estudo

\begin{tabular}{|c|c|c|c|c|c|}
\hline \multirow{2}{*}{\multicolumn{2}{|c|}{ Grupos de cluster }} & \multicolumn{3}{|c|}{ Grupos pré-definidos } & \multirow{2}{*}{ Tota } \\
\hline & & 1 & 2 & 3 & \\
\hline \multirow{3}{*}{ Valores } & 1 & 6 & 1 & 0 & 7 \\
\hline & 2 & 1 & 4 & 0 & 5 \\
\hline & 3 & 0 & 0 & 2 & 2 \\
\hline \multirow{3}{*}{$\%$} & 1 & 85,7 & 14,3 & 0 & 100 \\
\hline & 2 & 20 & 80 & 0 & 100 \\
\hline & 3 & 0 & 0 & 100 & 100 \\
\hline
\end{tabular}

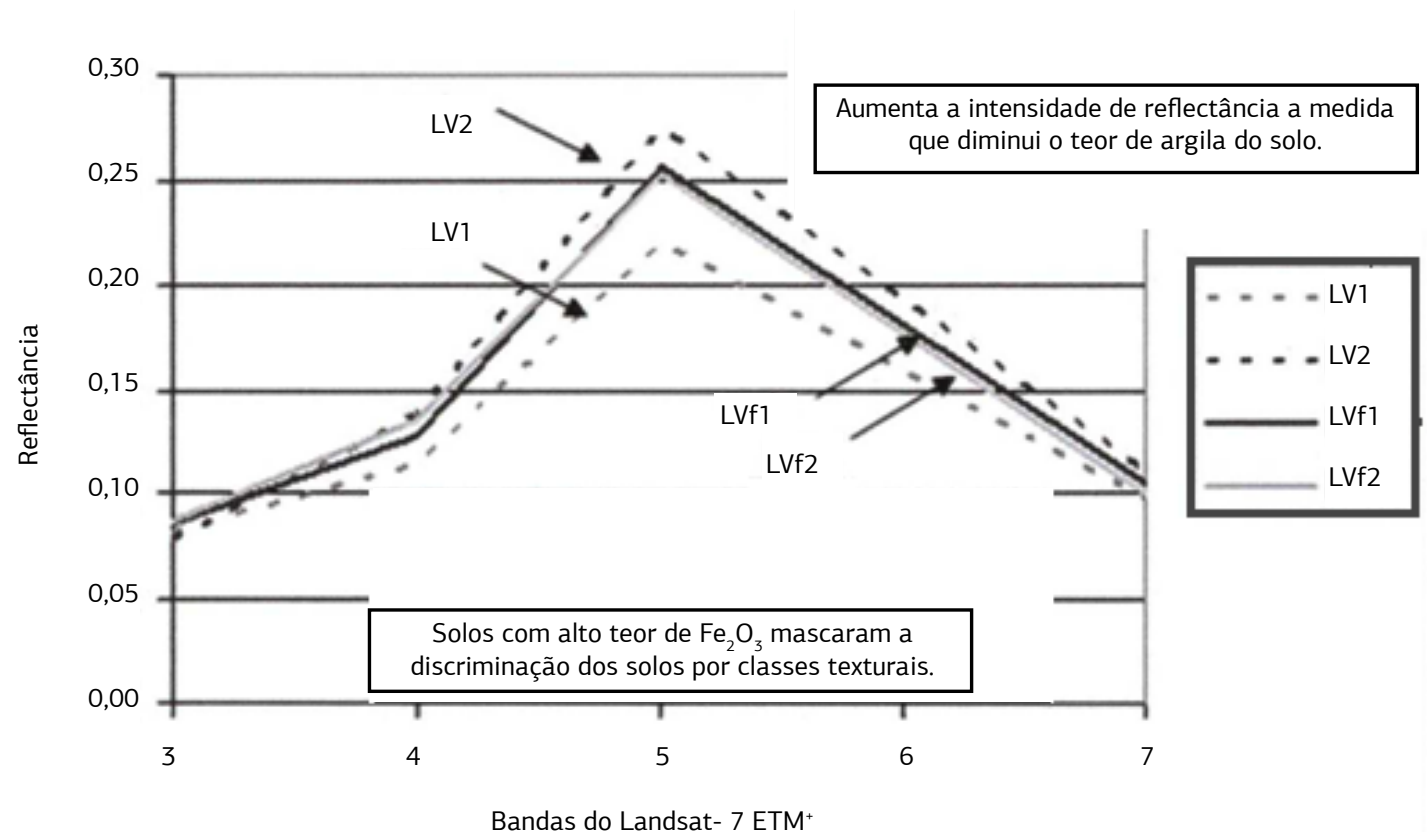

Figura 5. Curvas espectrais de diferentes solos obtidas a partir das reflectâncias das bandas ETM3 (630 - 690 nm), ETM4 (760 - 900 nm), EMT5 $(1150$ - $1750 \mathrm{~nm})$ e ETM7 $(2080$ - $2350 \mathrm{~nm})$ da imagem de satélite (Landsat-7TM+) da área de estudo. 
ferro presente nos solos da área de estudo (Latossolos e Nitossolos), ocasionando um deslocamento dos pontos em direçáo à banda do vermelho (ETM3: 630 - $760 \mathrm{~nm}$ ) e reduzindo o valor do $\mathrm{R}^{2}\left(\mathrm{R}^{2}=0,76\right)$.

Este tipo de resultado também foi observado por Nanni (2000) e Demattê et al. (2007), os quais verificaram valores de ajuste dos pontos da equação $\left(R^{2}\right)$ de 0,87 e 0,88 respectivamente.

$\mathrm{Na}$ figura 5, são apresentadas as curvas espectrais de quatro classes de solo da região de Maracaju (MS) presentes na imagem de satélite utilizada, isto é, Latossolo Vermelho distrófico típico textura muito argilosa (LV1); Latossolo Vermelho distrófico típico textura argilosa (LV2); Latossolo Vermelho distroférrico típico textura muito argilosa (LVf1); e Latossolo Vermelho Distroférrico típico textura argilosa (LVf2).

O LV1 foi o que teve a menor intensidade da reflectância entre as bandas analisadas e o LV2, a maior, enquanto os solos LVf1 e LVf2 foram muito similares entre si. $\mathrm{O}$ maior teor de argila do LV1 provavelmente ocasionou a menor intensidade de reflectância das bandas espectrais analisadas. Neste caso, NANNI (2000) explica que quanto maior o teor de argila, mais umidade o solo retém e maior é a absorção de energia radiante pelo solo, traduzindo-se em menor reflectância. Além disso, o LV2, por ser menos argiloso, também possui maiores teores de areia, que nestes solos têm mais de $95 \%$ de quartzo em sua constituição (EMBrAPA, 2006) e, portanto, aumenta a reflectância do solo.

O comportamento das curvas espectrais do LVf1 e LVf2 foi muito similar provavelmente devido a estas amostras serem ricas em óxidos de Fe pedogênicos, o que faz com que mesmo existindo variaçôes quanto à classe textural entre esses solos, sua resposta espectral seja mascarada (BEN-DOR, 2002). Neste estudo, os LVf estudados tiveram teores de $\mathrm{Fe}_{2} \mathrm{O}_{3}$ maior que $18 \%$ e menor que $36 \%$.

Individualmente, as bandas ETM4 (760 - $900 \mathrm{~nm})$ e ETM5 $(1550-1750 \mathrm{~nm})$ foram as que proporcionaram a maior variação da intensidade de reflectância entre os solos e, a partir da ETM5 ocorreu um decréscimo da intensidade de reflectância para todas as amostras. Óxidos de $\mathrm{Fe}$ absorvem energia radiante na banda ETM4 e a água nas bandas ETM5 e ETM7, mas principalmente na ETM7. Entretanto, mesmo existindo variação no teor de óxidos de Fe entre as amostras, essa discriminação não foi nítida, provavelmente devido à variaçáo de umidade do solo, a qual provavelmente é condicionada pela textura e se reflete nitidamente na banda ETM5.

No entanto, esse fato não impede que as informações espectrais da superfície dos solos, determinadas através da análise de imagens de satélite, sejam agregadas às informaçôes qualitativas do relevo e quantitativas da drenagem, obtidas pela fotointerpretação, com o intuito de se obter maior precisão probabilística na identificação das classes de solo existentes em um determinado local.

\section{CONCLUSÕES}

1. O Cambissolo Háplico foi o que mais se diferenciou em relação aos demais quanto às características qualitativas do relevo e da drenagem, enquanto os Latossolos e Nitossolos foram muito similares entre si.

2. A densidade de drenagem (Dd), determinada a partir da fotointerpretaçáo, possibilitou identificar amostras circulares contendo diferentes classes de solos $(0,31$ $\mathrm{km} \mathrm{km}^{-2}, 0,68 \mathrm{~km} \mathrm{~km}^{-2}$ e $1,26 \mathrm{~km} \mathrm{~km}^{-2}$ para as amostras contendo Latossolos, Nitossolos e Cambissolos, respectivamente) com um índice de acerto de 85,7\%.

3. Somente foi possível discriminar classes de solos em relação às suas variaçóes nas classes texturais através do uso das imagens do satélite; mas para solos teor de ferro total acima de $180 \mathrm{~g} \mathrm{~kg}^{-1}$, esta distinção foi prejudicada. No entanto, conjuntamente, a associação da avaliação de índices de drenagem com informaçôes geradas a partir das imagens de satélite podem auxiliar na identificação de solos na paisagem.

\section{REFERÊNCIAS}

BARET, F.; JACQUEMOUND, S.; HANOCQ, J.F;; The soil line concept in remote sensing. Remote Sensing of Environment, v.7, p.1-18, 1993.

BEN-DOR, E. Quantitative remote sensing of soil properties. Advances in Agronomy, v.75, p.173-243, 2002.

BIRKELAND, P.W. Soils and geomorphology. New York: Oxford University Press, 1984. 372p.

BRASIL. Departamento Nacional de Produção Mineral. Projeto Radam. Folha SF. 21 Campo Grande. Geologia, Geomorfologia, Solos, Vegetaçáo e Uso da Terra. v.28. Rio de Janeiro, 1982.

BURINGH, P. The applications of aerial photographs in soil surveys. In: Manual of photographic interpretation. Washington: American Society Photogrammetry, 1960. p.633-666.

CARVALHO, W.A.; FRANÇA, G.V.; CURI, P.R. Aplicação de análise multivariada na discriminaçáo de unidades de solo, mediante parâmetros morfométricos de bacias hidrográficas, em Botucatu, SP. Revista Brasileira de Ciências do Solo, v.14, p.195-203, 1990.

DEMATTÊ, J.A.M.; DEMÉTRIO, V.A. Caracterização de solos por padróes de drenagem e sua relação com índices de intemperismo. Pesquisa Agropecuária Brasileira, v.33, p.87-95, 1998.

DEMATTÊ, J.A.M.; GALDOS, M.V.; GUIMARÁES, R.V.; GENÚ, A.M.; NANNI, M.R.; ZULLO JUNIOR, J. Quantification of tropical soil attributes from ETM+/LANDSAT-7 data. International Journal of Remote Sensing, v.28, p.1-17, 2007.

DEMATTÊ, J. A. M.; DEMÉTRIO, V. A. Fotointerpretaçâo de padrôes de drenagem em amostras circulares na caracterização de solos basálticos do estado do Paraná. Revista Brasileira de Ciências do Solo, v.20, p. 109-115, 1996 a. 
DEMATTÊ, J.A.M.; DEMÉTRIO, V.A. Padrôes de drenagem em áreas de solos desenvolvidos de rochas vulcânicas ácidas na região de Guarapuava (PR). Revista Brasileira de Ciência do Solo, v.20, p.305-311, $1996 b$.

EMBRAPA - EMPRESA BRASILEIRA DE PESQUISA AGROPECUÁRIA. Procedimentos normativos de levantamentos pedológicos. Rio de Janeiro: Centro Nacional de Pesquisa de Solos, 1995. 101p.

EMBRAPA - EMPRESA BRASILEIRA DE PESQUISA AGROPECUÁRIA. Manual de métodos de análises de solo. 2.ed. Rio de Janeiro: Ministério da Agricultura e do Abastecimento, 1997. 212p.

EMBRAPA - EMPRESA BRASILEIRA DE PESQUISA AGROPECUÁRIA. Sistema brasileiro de classificação de solos. 2. ed. Rio de Janeiro: Embrapa Solos, 2006. 306p.

FRANÇA, G.V.; DEMATTÊ, J.A.M. Parâmetros da rede de drenagem de solos da regiāo de Iracemápolis (SP). Anais da Escola Superior de Agricultura "Luiz de Queiroz", v.47, p.541-545, 1990.

FRANÇA G.V; DEMATTÊ J.A.M. Levantamento de solos e interpretação fotográfica dos padróes de desenvolvimento em solos originados do Arenito de Bauru. Scientia Agricola, v.50, p.77-86, 1993.

GOOSEN, D. Interpretación de fotos aéreas y su importancia en levantamiento de suelos. Roma: FAO, 1968. 58 p. (Boletim sobre Suelos, n 6)

HUETE, A. R. Soil influences in remotely sensed vegetationcanopy spectra. In: G. ASRAR (Ed.). Theory and Application of Optical Remote Sensing. New York, 1989. p. 107-141.

INPE - INSTITUTO NACIONAL DE PESQUISAS ESPACIAIS. Spring Software version 4.0. São Jose dos Campos, SP, Brazil. (2003) Disponível em: http://www.inpe.br

LUEDER, D. R. Aerial photographic interpretation: principles and applications. New York: McGraw-Hill. 1959. 462p.
MANZOLI JUNIOR., W. Unidades de solos caracterizadas por ocupação, rede de drenagem e relevo de bacias hidrográficas no município de Sud-Mennucci, SP. 1990. 127f. Tese (Doutorado) Universidade Estadual Paulista, Botucatu.

MONIZ, A.C. Elementos de pedologia. São Paulo: Universidade de São Paulo, 1972. 459p.

MONIZ, A.C. Seqüência de evolução de solos derivados de arenito Bauru e de rochas básicas da região nordeste do Estado de São Paulo. Bragantia, v.22, p.309-335, 1973.

NANNI, M.R. Dados radiométricos obtidos em laboratório e no nível orbital na caracterização e mapeamento de solos. 2000. 366f. Tese (Doutorado) - Escola Superior de Agricultura Luiz de Queiroz, Universidade de São Paulo, Piracicaba.

PISSARRA, T. C. T.; POLITANO, W.; FERRAUdO, A. S. Avaliação de características morfométricas na relação solo-superfície da Bacia Hidrográfica do Córrego Rico, Jaboticabal (SP). Revista Brasileira de Ciência do Solo, v.28, p.297-305, 2004.

REDDY, G. P. O.; MAJI, A. K.; GAJBHIYE, K. S. Drainage morphometry and its influence on landform characteristics in a basaltic terrain, Central India - a remote sensing and GIS approach. International Journal of Applied Earth Observation and Geoinformation, v.6, p.1-16, 2004.

SANTOS, R. D. dos; LEMOS, R. C.; SANTOS, H. G. dos; KER, J. C.; ANJOS, L. H. C. dos. Manual de descrição e coleta de dolo no campo. 5.ed. (revisada e ampliada). Viçosa: Sociedade Brasileira de Ciência do Solo, 2005. 100p.

STRECK, E. V.; KÄMPF, N.; DALMOLIN, R. S. D.; KLAMT, E.; SCHNEIDER, P. NASCIMENTO, P. C. Solos do Rio Grande do Sul. Porto Alegre: EMATER/RS; UFRGS, 2002. 126p.

TANRÉ, D.; HOLBEN, B. N.; KAUFMAN, Y. J. Atmospheric correction algorithm for NOAA-A VHRR products: theory and application. IEEE-Transactions on Geoscience Remote Sensing, v.30, p. 231-248, 1992. 